\title{
Use of the Multispecies Probiotic Winclove 500/BactoSan pro FOS Leads to Less Gastrointestinal Complaints in Adults-An Observational In Vivo Pilot Study
}

\author{
Fritz Grossenbacher ${ }^{1}$, Agim Gashi1 ${ }^{1}$, Isolde Besseling-van der Vaart ${ }^{2}$ \\ ${ }^{1}$ Mediscope, Lyss, Switzerland \\ ${ }^{2}$ Winclove Probiotics B.V., Amsterdam, The Netherlands \\ Email: *i.besseling@winclove.nl
}

How to cite this paper: Grossenbacher, F., Gashi, A. and Besseling-van der Vaart, I. (2016) Use of the Multispecies Probiotic Winclove 500/BactoSan pro FOS Leads to Less Gastrointestinal Complaints in AdultsAn Observational In Vivo Pilot Study. Advances in Microbiology, 6, 975-985.

http://dx.doi.org/10.4236/aim.2016.614092

Received: October 20, 2016

Accepted: December 3, 2016

Published: December 7, 2016

Copyright (c) 2016 by authors and Scientific Research Publishing Inc. This work is licensed under the Creative Commons Attribution International License (CC BY 4.0).

http://creativecommons.org/licenses/by/4.0/

\begin{abstract}
The potential benefit of probiotics on the gut microbiota and on various gastrointestinal disorders is well documented. It has become clear that these probiotic effects are strain-specific, underlying the necessity for a well-founded strain selection for research and clinical practice. Whether probiotics also have a positive effect on parameters of gastrointestinal function in a healthy population is less investigated. The objective of this in vivo observational study was to investigate the effect of a 6-week intervention with a multispecies probiotic product on gut health and quality of life (QoL) in a population of otherwise healthy adults and to evaluate the feasibility of conducting a controlled trial on probiotic effects in this population. A total of 40 participants from 3 different health centres were included in the study. After a 1week inclusion phase, participants were supplemented for a 6-week period with Winclove 500/BactoSan pro FOS. During the run-in phase and each week during the observational period, gastrointestinal functional parameters were documented by an adapted version of the Eypasch questionnaire. Data on QoL was collected at baseline and at the end of the intervention period. The total gastrointestinal (GI) symptom score was reduced from $10(4-21)$ at baseline to $6(0-15)(\mathrm{p}<0.05)$ after 6 weeks intervention. More specifically, after the probiotic intervention the percentage of participants which were fully resolved of a particular symptom significantly increased to $27.5 \%(\mathrm{p}<0.02)$ for gastrointestinal pain, to $25 \%(\mathrm{p}<0.03)$ for epigastric fullness/bloating and to $20 \%(\mathrm{p}<0.02)$ for flatulence, compared to baseline. The treatment was well-tolerated. This observational study provides important information on the ability to investigate potential effects of a probiotic product in otherwise healthy adults. The promising results Winclove 500/BactoSan pro FOS showed on
\end{abstract}


gut health and QoL in this target group should be further investigated in a randomized, placebo-controlled study.

\section{Keywords}

Probiotics, Healthy Volunteers, Gut Health, Quality of Life and Abdominal Pain

\section{Introduction}

Gastrointestinal symptoms, such as flatulence, bloating, constipation and diarrhoea, are among the most frequent occurring symptoms in the general population. A survey among American adults showed that $41 \%$ experienced gastrointestinal symptoms when recording symptoms for one month. Flatulence affected $16 \%$ of the adults, whereas $22 \%$ reported abdominal pain and $27 \%$ had experienced diarrhoea [1]. This was confirmed by a second survey conducted in the U.S., which demonstrated that flatulence was prevalent in $19 \%$ of the adult population [2]. Gastrointestinal symptoms are frequent, also in otherwise healthy people, but mostly known to occur as the expression of a functional gastrointestinal disease, whereby irritable bowel syndrome (IBS), gastroesophageal reflux and functional dyspepsia are the most common manifestations and often overlap [3]. Even though gastro-intestinal symptoms are common in the general population they often might not reach clinical relevance.

An important factor facilitating gastrointestinal functioning is the microbial composition of the GI-tract [4]. The microbiota, increasing in density along the different parts of the GI-tract, plays a key role in health and disease through their involvement in metabolic, nutritional, physiological and immunological processes in the host [5] [6]. It exerts important metabolic activities by extracting energy from otherwise indigestible dietary polysaccharide, leading to the production of important nutrients, such as short-chain fatty acids (SCFA) and vitamins [7]. Furthermore, the microbiota protects the host from pathogens by colonisation resistance and production of antimicrobial compounds, and from systemic inflammation by strengthening the intestinal barrier function and modulating the mucosal immune system [8].

Different external factors, such as the use of medicines, specifically antibiotics, change of diet or stress can influence the microbial composition and can lead to intestinal dysbiosis [7]. Gastrointestinal dysbiosis is characterized by disturbed homeostasis of the microbiota with expansion of the pathogenic microbes, reduction of microorganism diversity and loss of beneficial bacterial strains [9]. On the other hand, the microbiota can be positively influenced with pro-, pre- and synbiotics, as many studies have shown during the last decades [10].

Probiotics are defined as "live microorganisms that, when administered in adequate amounts, confer a health benefit on the host' by the expert consensus document of The International Scientific Association for Probiotics and Prebiotics [11]. The positive effects of probiotics in various gastrointestinal diseases such as irritable bowel syndrome (IBS), inflammatory bowel diseases (IBD), antibiotic-associated or infectious diarrhoea 
or necrotizing enterocolitis have been demonstrated in various clinical studies [12] [13]. Regularly, the clinical evidence is summarized in recommendations [14] [15]. Investigating the effect of probiotics in healthy persons has been very limited, but did show promising effects on bowel function [16] [17] Based on the physiological importance of the intestinal microbiota there are sufficient indications that probiotics should be able to contribute to the maintenance of gastrointestinal health and quality of life in healthy persons [1].

The objective of this pilot in vivo observational study is therefore to get insight in the potential effects of multispecies probiotic food supplement Winclove 500/BactoSan pro FOS on the quality of life (QoL) and intestinal health in a population not diagnosed with a gastrointestinal disease but with recent non-specific GI-complaints. Since it becomes more recognized that the patient's experience (perception?) of complaints and the disease is very relevant for their actual health status, our research was not only focused on gastrointestinal symptoms but also on the impact of these symptoms on the quality of life of the patient. Additionally, the study is setup to test the feasibility to perform a controlled in vivo study in this specific target group and to evaluate the number of participants requested for a controlled study.

\section{Materials and Methods}

\subsection{Study Population and Criteria}

In total 44 volunteers with recent non-specific gastrointestinal (GI)-complaints were participating in the study. As all of them were recruited by therapists of three different health centres (Paramed in Baar; Purahira in Solothurn and Swiss Prävensana Aktimed in Rapperswil) in Switzerland, temporary bowel complaints such as constipation, bloating, flatulence and abdominal pain were the reasons of their visit. Included subjects were not clinically diagnosed as IBS-patient, and persons suffering from diseases like chronic inflammatory bowel diseases (IBD) or those taking antibiotics or other remedies to alleviate intestinal complaints (including pro- and prebiotic use) were excluded from the study. Participants were informed about the observational study and after giving their informed consent they were included.

\subsection{Study Design}

Between March and October 2014 the observational study was performed in three Swiss clinical centres. The study started with a run-in period of 1 week, in which baseline gastrointestinal functional parameters were documented at the beginning and end of the week (week 0) by means of a validated and adapted questionnaire according to Eypasch [18]. In addition, information concerning the quality of life (general wellness, state of health, state of energy), athletic activities and eating and drinking habits were collected at baseline.

Subsequently, subjects received once daily one sachet containing 3 grams of the freeze-dried multispecies probiotic Winclove 500 (Winclove Probiotics, Amsterdam, the Netherlands), on the market as Bactosan pro FOS (Mepha, Basel, Switzerland) for a 
period of 6 weeks. Participants dissolved the powder in water, and were asked to drink it before going to sleep. The product contains the following bacterial strains: Bifidobacterium lactis W51, Bifidobacterium lactis W52, Enterococcus faecium W54, Lactobacillus acidophilus W22, Lactobacillus paracasei W20, Lactobacillus plantarum W21, Lactobacillus salivarius W24 and Lactococcus lactis W19, with a total viable cell count of $1 \times 109 \mathrm{cfu} / \mathrm{gram}$, and therefore $3 \times 109 \mathrm{cfu} /$ daily dose. The selected strains work on three levels of action [19]: directly in microbe-microbe interaction level, which takes place in the intestinal lumen, secondly by strengthening the intestinal barrier function and thirdly by modulation of the immune system, which makes this formulation a broad-spectrum probiotic supplement. The bacterial strains are combined with a mineral mix (combination of potassium chloride, magnesium sulphate and manganese sulphate), inulin, fructo-oligosaccharides (FOS), amylases, maize starch and maltodextrins. All these ingredients are added to the probiotic formulation to ensure stability, GI-survival and biological activity of the probiotic strains.

After the 1 week run-in phase, self-reported data on gastrointestinal functional parameters were documented during 6 weeks at the end of each week using the adapted Eypasch-questionnaire. At the completion of the 6-week intervention period the quality of life was self-reported by using the adapted Eypasch questionnaire. At the end of the study satisfaction of the probiotic use, tolerance and compliance was recorded.

\subsection{Statistical Analysis}

Q-Q plots and Shapiro-Wilk statistics from SPSS were used to evaluate data normality. Proportions, corresponding two-proportion tests with continuity correction and power calculations are performed using R. Approximate and exact non-parametric tests are performed using Wilcoxon signed-rank test \& exact Wilcoxon signed-rank test (zeros handled a la Pratt) from coin package in R. Using SPSS, measurement of association is based on the rank-order association using Spearman's rho statistics and verified by corresponding plots. The sample size for a study with control group and with the requirement to have the same size effect as calculated in this study, are evaluated using $\mathrm{G}^{\star}$ Power software. A p-value $<0.05$ was defined as significant. Versions of statistical software used: IBM SPSS Statistics v.22; R 2.15.1; GPower 3.1.

\section{Results}

A total of 44 volunteers, aged between 21 and 70 years old were recruited for the study. Four participants did not complete the questionnaires and were lost in follow-up for unknown reasons and were therefore not included in the analysis. The majority of the participants are women (80\%). Mean BMI was 22.5, ranging from 17.5 to 33 . Furthermore, the data shows that participants mainly followed a healthy lifestyle as the majority of the participants met recommended criteria considering physical activities, fruit, vegetables and whole grain intake as well as drinking behaviour [20]. At baseline 20\% of the participants stated that they regularly use medications other than antibiotics or gastrointestinal drugs. Neither the indication nor the type of medication was docu- 
mented at baseline as this was not used for study purposes. All demographic details of the study population (per protocol) measured at baseline are listed in Table 1.

Gastrointestinal symptoms were self-reported both at baseline, as well as during the intervention period on a weekly basis. The original questionnaire of Eypasch evaluates gastrointestinal symptoms by the frequency patients suffered from a particular symptom during the past 2 weeks on a scale from $0-4(0=$ never, $4=$ all the time $)$. In this study an adapted version of the questionnaire was used, which also included an evaluation about the severity (burden) of a particular symptom using a scale from $0-4$ ( $0=$ no trouble, $4=$ maximal trouble). The state of health and quality of life (QoL) were documented both on baseline as well as after 6 weeks of intervention, reporting on a scale from 1 - 10, whereby 10 corresponds to a maximum state of well-being.

Table 1. Baseline characteristics.

\begin{tabular}{|c|c|}
\hline Number of subjects & 40 \\
\hline Age in years & $41(21-70)$ \\
\hline Sex (female), n (\%) & $32(80 \%)$ \\
\hline BMI & $22.5(17.5-33)$ \\
\hline \multicolumn{2}{|l|}{ Physical activities, $\mathrm{n}(\%)$} \\
\hline - Several times a week & $14(35 \%)$ \\
\hline - Regularly & $18(45 \%)$ \\
\hline - Rarely & $8(20)$ \\
\hline \multicolumn{2}{|l|}{ Fruit consumption, $\mathrm{n}(\%)$} \\
\hline - several times a day & $20(50 \%)$ \\
\hline - once a day & $13(33 \%)$ \\
\hline - several times a week & $5(12 \%)$ \\
\hline - once a week & $2(5 \%)$ \\
\hline \multicolumn{2}{|l|}{ Vegetable consumption, $\mathrm{n}(\%)$} \\
\hline - several times a day & $16(40 \%)$ \\
\hline - once a day & $20(50 \%)$ \\
\hline - several times a week & $3(8 \%)$ \\
\hline - once a week & $1(2 \%)$ \\
\hline \multicolumn{2}{|l|}{ Whole grain consumption, $\mathrm{n}(\%)$} \\
\hline - several times a day & $5(13 \%)$ \\
\hline - once a day & $26(65 \%)$ \\
\hline - several times a week & $6(15 \%)$ \\
\hline - once a week & $3(7 \%)$ \\
\hline \multicolumn{2}{|l|}{ Liquid intake, n (\%) } \\
\hline$\bullet>1.5 \mathrm{~L}$ per day & $28(70 \%)$ \\
\hline - 1 - $1.5 \mathrm{~L}$ per day & $12(30 \%)$ \\
\hline \multicolumn{2}{|l|}{ Medication } \\
\hline Medication intake, $\mathrm{n}(\%)$ & $8(20 \%)$ \\
\hline
\end{tabular}


Table 2 shows the results of gastrointestinal symptoms and QoL parameters after 6 week of treatment compared to baseline.

\subsection{Gastrointestinal Symptoms}

The baseline data of the study show that gastrointestinal symptoms are common in the participating adults, which was also expected as the included subjects all came to the

Table 2. Gastrointestinal symptoms and quality of life after 6 week of treatment compared to baseline.

\begin{tabular}{|c|c|c|c|c|c|}
\hline \multirow[t]{2}{*}{$\begin{array}{l}\text { Severity of gastrointestinal symptoms } \\
\text { (during the last } 2 \text { weeks) }(n=40)\end{array}$} & \multicolumn{2}{|c|}{$\begin{array}{l}0=\text { no, } 4=\max \\
\text { Median, range }\end{array}$} & \multicolumn{3}{|c|}{$\begin{array}{c}\text { Percentage of patients that } \\
\text { reported no symptoms, scoring ' } 0 \text { ' } \\
(\%)\end{array}$} \\
\hline & Baseline & $\begin{array}{l}\text { End of } \\
\text { study }\end{array}$ & Baseline & $\begin{array}{l}\text { End of } \\
\text { study }\end{array}$ & $\mathrm{p}$-value \\
\hline Diarrhoea & $0(0-3)$ & $0(0-2)$ & $67.5 \%$ & $75 \%$ & $\mathrm{p}=0.62$ \\
\hline Constipation & $1(0-3)$ & $0(0-3)$ & $37.5 \%$ & $52.5 \%$ & $\mathrm{p}=0.26$ \\
\hline Feeling of incomplete evacuation & $1(0-4)$ & $0(0-3)$ & $42.5 \%$ & $57.5 \%$ & $\mathrm{p}=0.26$ \\
\hline Straining to evacuate & $0(0-4)$ & $0(0-2)$ & $50 \%$ & $65 \%$ & $\mathrm{p}=0.26$ \\
\hline Bloating & $3(0-4)$ & $1(0-3)$ & $10 \%$ & $20 \%$ & $\mathrm{p}=0.35$ \\
\hline \multirow[t]{2}{*}{$\begin{array}{l}\text { Frequency of gastrointestinal } \\
\text { symptoms } \\
\text { (during the last } 2 \text { weeks) }(\mathrm{n}=40)\end{array}$} & \multicolumn{2}{|c|}{$\begin{aligned} 0= & \text { never, } 4=\text { always, } \\
& \text { Median, range }\end{aligned}$} & \multicolumn{3}{|c|}{$\begin{array}{l}\text { Percentage of patients that } \\
\text { reported never having symptoms, } \\
\text { scoring "0" (\%) }\end{array}$} \\
\hline & Baseline & $\begin{array}{l}\text { End of } \\
\text { study }\end{array}$ & Baseline & $\begin{array}{l}\text { End of } \\
\text { study }\end{array}$ & p-value \\
\hline Epigastric pain & $1(0-3)$ & $1(0-2)$ & $17.5 \%$ & $45 \%$ & $\mathrm{p}=0.02^{\star}$ \\
\hline Epigastric fullness & $2(0-3)$ & $1(0-2)$ & $17.5 \%$ & $42.5 \%$ & $\mathrm{p}=0.03^{\star}$ \\
\hline Belching & $2(0-3)$ & $1(0-3)$ & $7.5 \%$ & $15 \%$ & $\mathrm{p}=0.48$ \\
\hline Flatulence & $2(0-3)$ & $1(0-3)$ & $2.5 \%$ & $22.5 \%$ & $\mathrm{p}=0.02^{\star}$ \\
\hline Frequent bowel movements & $0(0-3)$ & $0(0-3)$ & $67 \%$ & $75 \%$ & $\mathrm{p}=0.62$ \\
\hline Diarrhoea & $0(0-2)$ & $0(0-2)$ & $72 . \%$ & $72 \%$ & \\
\hline \multirow{2}{*}{$\begin{array}{l}\text { Combined Endpoint of all } \\
\text { gastrointestinal symptoms (Frequency } \\
\text { and severity) }(\mathrm{n}=37)\end{array}$} & \multicolumn{2}{|c|}{$\begin{array}{c}0=\min , 40=\max \\
\text { Median, range }\end{array}$} & & & \\
\hline & Baseline & $\begin{array}{l}\text { End of } \\
\text { study }\end{array}$ & & & p-value \\
\hline Combined gastrointestinal symptoms & $10(4-21)$ & $6(0-15)$ & & & $\mathrm{p} \leq 0.05^{*}$ \\
\hline \multirow[t]{2}{*}{ Quality of Life ( $n=40)$} & \multicolumn{2}{|c|}{$\begin{array}{c}0=\min , 10=\max \\
\text { Median, range }\end{array}$} & & & \\
\hline & Baseline & $\begin{array}{l}\text { End of } \\
\text { study }\end{array}$ & & & \\
\hline General wellness & $7(3-10)$ & $8(4-10)$ & & & \\
\hline State of health & $9(3-10)$ & $9(3-10)$ & & & \\
\hline State of energy & $7(2-10)$ & $8(2-10)$ & & & \\
\hline
\end{tabular}


therapists with non-specific GI-complaints as reason. A substantial percentage of participants reported to have symptoms like epigastric pain, epigastric fullness, belching, bloating and flatulence. Except for bloating, where the severity of the symptom reaches 3 out of max. 4 points at baseline, the symptoms reported were mostly mild and moderate in terms of severity and frequency. We observed however some inconsistency in reporting severity and frequency of symptoms. For instance when looking at diarrhoea at baseline in the severity score $67.5 \%$ of patients reported not having the symptom whereas in the frequency score $72 \%$ reported never having had diarrhoea during the past 2 weeks.

Besides analysing each symptom separately, the total symptom score was calculated as the sum of the individual scores on the adapted Eypasch questionnaire with a scale of 0 - 40, whereby 0 corresponded to no symptoms and 40 corresponded to maximum symptoms. For the aforementioned reason, three participants of the per-protocol study population were excluded from the total analysis because of contradictory, invalid data (specified severe symptoms under severity, but simultaneously indicated never having had the corresponding symptoms under the frequency). In the 37 participants, at baseline the median for the combined symptom score was $10(4-21)$ and changed by the end of the study to $6(0-15)$, demonstrating a significant improvement of 4 points $(\mathrm{p}<$ $0.05)$.

Results on frequency of symptoms were also expressed as the percentage of subjects reporting to be asymptomatic. It was shown that for epigastric pain, epigastric fullness and flatulence the number of subjects reporting to be asymptomatic after 6 weeks of probiotic use, was significantly higher for each of these three complaints compared to baseline. With the exception of frequent diarrhoea and nausea, the other documented symptoms also exhibited a slight increase in the number of persons who were asymptomatic after 6 weeks of intervention, although this was not significant.

More specifically, for the three parameters showing to be significantly improved over time, the number of participants who became asymptomatic increased already after one week of intervention although not yet significant, as shown in Figure 1. This increase continued for the duration of the entire observation period, whereby the improvement in abdominal pain for which the proportion of asymptomatic persons showed the highest increase, namely a significant raise from $17.5 \%$ at the beginning of the study to $45 \%$ at the end of the study $(\mathrm{p}<0.02)$. A significant improvement was likewise shown in epigastric fullness for which the absence of symptoms increased from $17.5 \%$ to $42.5 \%$ $(\mathrm{p}<0.03)$ and in the symptom of frequent flatulence for which the absence of symptoms increased from $2.5 \%$ to $22.5 \%$ ( $\mathrm{p} \leq 0.02)$.

\subsection{Quality of Life}

The parameters on the quality of life (energy status, well-being, state of health) showed a slight improvement after 6 weeks of intervention in comparison to baseline, however, this difference was not significant. Despite this good assessment of the health and energy status, $55 \%$ of the participants reported to have suffered from fatigue during the 


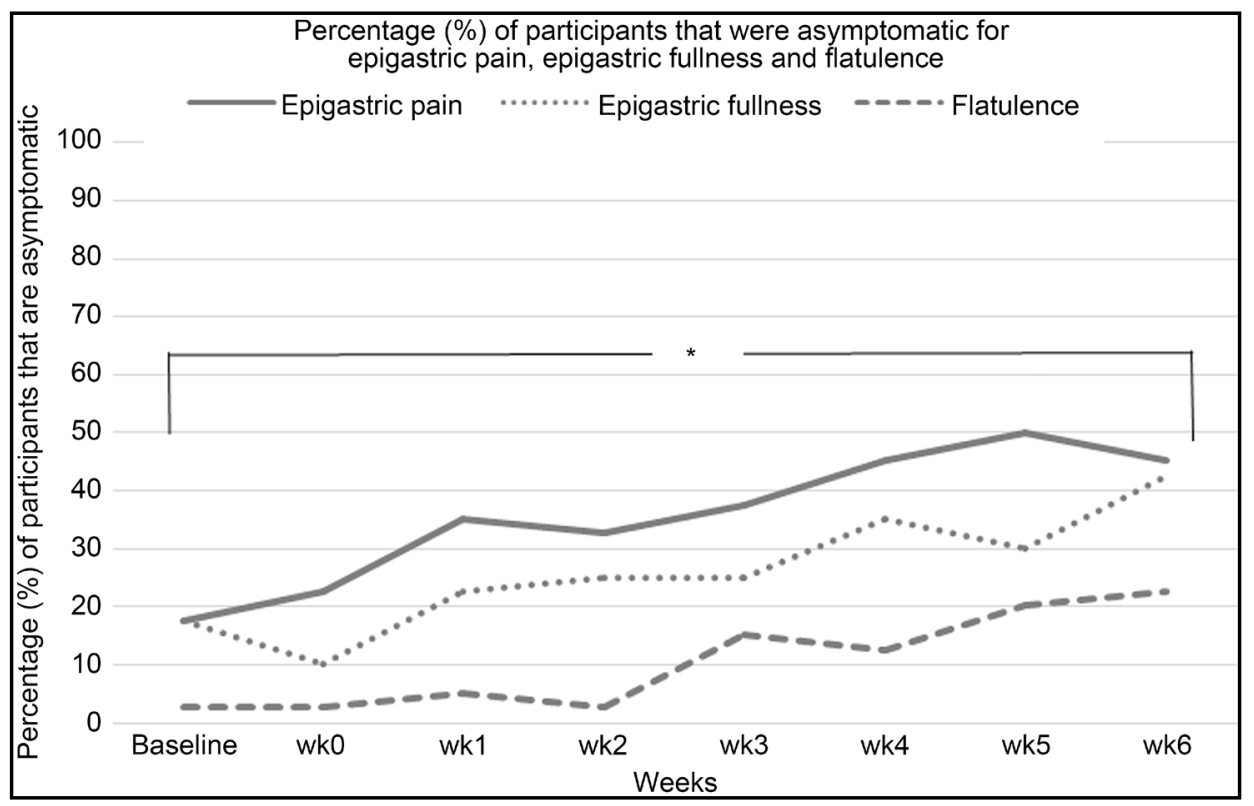

Figure 1. Percentage of participants reported to be asymptomatic for epigastric pain (line), epigastric fullness (dotted line) or flatulence (striped line). ${ }^{*} \mathrm{p}<0.05$.

last 6 weeks prior to the study. Half of this group usually felt tired and the other half even reported to be always tired (data not shown).

\subsection{Tolerance}

After the 6-week probiotic use, $66 \%$ of the study participants reported to be satisfied with the effect on intestinal function and $98 \%$ evaluated the product as well-tolerated (data not shown).

\section{Discussion}

The data of this observational study indicates that a specific multispecies probiotic product might contribute to the maintenance and improvement of intestinal health and by that may have a positive influence on quality of life in otherwise healthy adults.

Since the study was performed on subjects who visited the therapist for non-specific gastrointestinal complaints, it could be noticed that at the beginning of the study a relatively high percentage of the participants was not asymptomatic with regard to several symptoms, whereby bloating was mostly reported and at baseline even present in $90 \%$ of the participants. Furthermore the majority of the study subjects reported to suffer from abdominal pain, sensation of epigastric fullness, belching and flatulence as well. This might suggest that among the study participants there were subjects with 'unrecognized' IBS or at least with gastrointestinal symptoms that did not reach clinical relevance.

The increase of the percentage of patients which reported to be resolved of certain gastrointestinal symptoms after 6 weeks of probiotic consumption are in line with previous performed studies showing positive effects on relief of GI-symptoms by probiotic 
supplementation in healthy volunteers [16] [17] [21].

Although participants did not report to be completely asymptomatic for most of the questioned GI-complaints at baseline, quality of life (QoL) was already quite high at that time and therefore the observed changes were less pronounced. Parameters influencing the QoL depend, however, on various external and internal factors, which were also not all documented in this study.

This study shows that single items of the adapted questionnaire according to Eypasch have limited suitability for investigating an otherwise healthy population. Since the investigation in such a target group is missing inclusion criteria based on an existing disease or clearly defined symptoms, the parameter value of particular symptoms might be small in effect size. For example this can been seen in the contradictory results on energy levels and tiredness; the median energy status was scored at 7 at baseline and not-significantly changing after 6 weeks of intervention, while a large proportion of the group reported to feel usually or even always tired as well.

The approach to form a combined endpoint with summation of the individual symptoms, appears to be an option for increasing the effect size and thus the statistical strength of the investigation in such a population, although this might result in an overestimation of the effect. The validity of such a combined symptom score, should be further investigated. Considering the occurrence, observed significance and effect size, the adaption of the questionnaire by Eypasch by combining the endpoints could, on the other hand, help to reduce the requested sample size in a rather healthy population. Assuming a $90 \%$ power and a $\mathrm{p}<0.05$, the sample size that would be necessary in a placebo-controlled study to get the same effect size as observed in the current observational study will vary between 120 and 1540 depending on the symptom measured. By using a 40-point scale as combined endpoint of all gastrointestinal symptoms, a sample size of around 80 is requested.

The statistical analyses show that the differences observed in this observational study are however not due to chance and with a certain probability can be attributed to Winclove 500/BactoSan pro FOS. Nevertheless, the study was designed as observational study without a control group, whereby the effects were not corrected for a possible placebo-effect. It is known that a relative high placebo-effect is often seen in studies investigating the effect of probiotics in IBS-patients [22]. Furthermore as this pilot study was undertaken in an otherwise healthy population and did not have a control group, the self-limitation potential of the evaluated symptoms during a 6-week period cannot be estimated.

An effect on the results due to confounding factors or bias cannot be ruled out either Therefore the concept of probiotic interventions in a rather healthy population deserves further evaluation, for example in an observational study with a control group or in randomised placebo-controlled clinical trial.

\section{Conclusion}

Our observational study shows that gastrointestinal symptoms are quite common in 
otherwise healthy adults. The observed results indicate that a 6-week intervention with a specifically designed multispecies probiotic product (Winclove 500/Bactosan pro FOS) seems to influence relief of gastrointestinal symptoms, especially epigastric pain, epigastric fullness and flatulence in a positive way. This observational study demonstrates it is feasible to measure influences of probiotics in an otherwise healthy target group, but this should be confirmed in a randomized, placebo-controlled study. Both pre-selection of subjects based on their complaints, as well as consolidating gastrointestinal symptoms parameters in a combined scale may increase the observed size effect and helps to reduce the sample size requested in such a trial.

\section{Acknowledgements}

We thank all the participants and the therapists involved in this study for their willingness to take part in this trial. We are very grateful to the work of Thomas Weikert and Patrick Hettrich (Mepha, Switzerland) who greatly supported this observational study. Our gratitude goes as well to Elske van Dijk and Yorick Tromp, who critically read the manuscript.

\section{References}

[1] Sandler, R.S., Stewart, W.F., Liberman, J.N., Ricci, J.A. and Zorich, N.L. (2000) Abdominal pain, Bloating, and Diarrhea in the United States: Prevalence and Impact. Digestive Diseases and Sciences, 45, 1166-1171. https:/doi.org/10.1023/A:1005554103531

[2] Jiang, X., Locke 3rd, G.R., Choung, R.S., Zinsmeister, A.R., Schleck, C.D. and Talley, N.J. (2008) Prevalence and Risk Factors for Abdominal Bloating and Visible Distention: A Population-Based Study. Gut, 57, 756-763. https:/doi.org/10.1136/gut.2007.142810

[3] Rasmussen, S., Jensen, T.H., Henriksen, S.L., Haastrup, P.F., Larsen, P.V., Sondergaard, J. and Jarbol, D.E. (2015) Overlap of Symptoms of Gastroesophageal Reflux Disease, Dyspepsia and Irritable Bowel Syndrome in the General Population. Scandinavian Journal of Gastroenterology, 50, 162-169. https:/doi.org/10.3109/00365521.2014.983157

[4] Collins, S.M., Denou, E., Verdu, E.F. and Bercik, P. (2009) The Putative Role of the Intestinal Microbiota in the Irritable Bowel Syndrome. Digestive and Liver Disease, 41, 850-853. https:/doi.org/10.1016/j.dld.2009.07.023

[5] Gerritsen, J., Smidt, H., Rijkers, G.T. and de Vos, W.M. (2011) Intestinal Microbiota in Human Health and Disease: The Impact of Probiotics. Genes \& Nutrition, 6, 209-240. https:/doi.org/10.1007/s12263-011-0229-7

[6] O'hara, A.M. and Shanahan, F. (2006) The Gut Flora as a Forgotten Organ. EMBO Reports, 7, 688-693

[7] Hawrelak, J.A. and Myers, S.P. (2004) The Causes of Intestinal Dysbiosis: A Review. Alternative Medicine Review, 9, 180-197.

[8] Martin, R., Miquel, S., Ulmer, J., Langella, P. and Bermudez-Humaran, L.G. (2014) Gut Ecosystem: How Microbes Help Us. Beneficial Microbes, 5, 219-233. https:/doi.org/10.3920/BM2013.0057

[9] Petersen, C. and Round, J.L. (2014) Defining Dysbiosis and Its Influence on Host Immunity and Disease. Cellular Microbiology, 16, 1024-1033. https:/doi.org/10.1111/cmi.12308

[10] Scott, K.P., Antoine, J.M., Midtvedt, T. and van Hemert, S. (2015) Manipulating the Gut Microbiota to Maintain Health and Treat Disease. Microbial Ecology in Health and Disease, 
26, 25877. https:/doi.org/10.3402/mehd.v26.25877

[11] Hill, C., Guarner, F., Reid, G., Gibson, G.R., Merenstein, D.J., Pot, B., Morelli, L., Canani, R.B., Flint, H.J., Salminen, S., Calder, P.C. and Sanders, M.E. (2014) Expert Consensus Document: The International Scientific Association for Probiotics and Prebiotics Consensus Statement on the Scope and Appropriate Use of the Term Probiotic. Nature Reviews Gastroenterology \& Hepatology, 11, 506-514. https:/doi.org/10.1038/nrgastro.2014.66

[12] Moayyedi, P., Ford, A.C., Talley, N.J., Cremonini, F., Foxx-Orenstein, A.E., Brandt, L.J. and Quigley, E.M. (2010) The Efficacy of Probiotics in the Treatment of Irritable Bowel Syndrome: A Systematic Review. Gut, 59, 325-332. https:/doi.org/10.1136/gut.2008.167270

[13] Ritchie, M.L. and Romanuk, T.N. (2012) A Meta-Analysis of Probiotic Efficacy for Gastrointestinal Diseases. PLoS ONE, 7, Article ID: e34938.

https:/doi.org/10.1371/journal.pone.0034938

[14] Floch, M.H., Walker, W.A., Sanders, M.E., Nieuwdorp, M., Kim, A.S., Brenner, D.A., Qamar, A.A., Miloh, T.A., Guarino, A., Guslandi, M., Dieleman, L.A., Ringel, Y., Quigley, E.M. and Brandt, L.J. (2015) Recommendations for Probiotic Use-2015 Update: Proceedings and Consensus Opinion. Journal of Clinical Gastroenterology, 49, S69-S73. https:/doi.org/10.1097/mcg.0000000000000420

[15] Sanders, M.E., Guarner, F., Guerrant, R., Holt, P.R., Quigley, E.M., Sartor, R.B., Sherman, P.M. and Mayer, E.A. (2013) An Update on the Use and Investigation of Probiotics in Health and Disease. Gut, 62, 787-796. https:/doi.org/10.1136/gutjnl-2012-302504

[16] Silvi, S., Verdenelli, M.C., Cecchini, C., Coman, M.M., Bernabei, M.S., Rosati, J., De Leone, R., Orpianesi, C. and Cresci, A. (2014) Probiotic-Enriched Foods and Dietary Supplement Containing SYNBIO Positively Affects Bowel Habits in Healthy Adults: An Assessment Using Standard Statistical Analysis and Support Vector Machines. International Journal of Food Sciences and Nutrition, 65, 994-1002. https:/doi.org/10.3109/09637486.2014.940284

[17] Verdenelli, M.C., Silvi, S., Cecchini, C., Orpianesi, C. and Cresci, A. (2011) Influence of a Combination of Two Potential Probiotic Strains, Lactobacillus rhamnosus IMC 501(R) and Lactobacillus paracasei IMC 502(R) on Bowel Habits of Healthy Adults. Letters in Applied Microbiology, 52, 596-602. https:/doi.org/10.1111/j.1472-765X.2011.03042.x

[18] Eypasch, E., Wood-Dauphinee, S., Williams, J.I., Ure, B., Neugebauer, E. and Troidl, H. (1993) The Gastrointestinal Quality of Life Index. A Clinical Index for Measuring Patient Status in Gastroenterologic Surgery. Chirurg, 64, 264-274.

[19] Timmerman, H.M., Koning, C.J., Mulder, L., Rombouts, F.M. and Beynen, A.C. (2004) Monostrain, Multistrain and Multispecies Probiotics-A Comparison of Functionality and Efficacy. International Journal of Food Microbiology, 96, 219-233. https:/doi.org/10.1016/j.ijfoodmicro.2004.05.012

[20] Hercberg, S., Chat-Yung, S. and Chaulia, M. (2008) The French National Nutrition and Health Program: 2001-2006-2010. International Journal of Public Health, 53, 68-77. https:/doi.org/10.1007/s00038-008-7016-2

[21] Del Piano, M., Carmagnola, S., Anderloni, A., Andorno, S., Ballare, M., Balzarini, M., Montino, F., Orsello, M., Pagliarulo, M., Sartori, M., Tari, R., Sforza, F. and Capurso, L. (2010) The Use of Probiotics in Healthy Volunteers with Evacuation Disorders and Hard Stools: A Double-Blind, Randomized, Placebo-Controlled Study. Journal of Clinical Gastroenterology, 44, S30-S34. https:/doi.org/10.1097/MCG.0b013e3181ee31c3

[22] Manheimer, E., Cheng, K., Wieland, L.S., Min, L.S., Shen, X., Berman, B.M. and Lao, L. (2012) Acupuncture for Treatment of Irritable Bowel Syndrome. Cochrane Database of Systematic Reviews, 5, Article ID: CD005111. https:/doi.org/10.1002/14651858.cd005111.pub3 
Submit or recommend next manuscript to SCIRP and we will provide best service for you:

Accepting pre-submission inquiries through Email, Facebook, LinkedIn, Twitter, etc. A wide selection of journals (inclusive of 9 subjects, more than 200 journals)

Providing 24-hour high-quality service

User-friendly online submission system

Fair and swift peer-review system

Efficient typesetting and proofreading procedure

Display of the result of downloads and visits, as well as the number of cited articles

Maximum dissemination of your research work

Submit your manuscript at: http://papersubmission.scirp.org/

Or contact aim@scirp.org 